\title{
ACCEPTANCE OF WEB-BASED TRAINING SYSTEM AMONG PUBLIC SECTOR EMPLOYEES
}

\author{
${ }^{1}$ Huda Ibrahim \& ${ }^{2}$ Thamer Ahmad AL-Rawashdeh \\ ${ }^{1}$ School of Computing, Universiti Utara Malaysia, Malaysia \\ ${ }^{2}$ Faculty of Science and Information Technology, \\ Al-Zaytoonah University of Jordan, Jordan
}

huda753@uum.edu.my; thamer_com@yahoo.com

\begin{abstract}
Applying web-based training system is highly preferable in meeting time constraints, however, its success is subject to users' acceptance. Previous studies highlight human challenge as the most important barrier in the implementation of an ICT-based training system. Users tend to show resistance in using new technology and online approaches. They favour the traditional way such as the face-to-face method of training. This paper presents the results of a study conducted to assess the acceptance of a web-based training by public sector employees. The study applied the Unified Theory of Acceptance and Use Technology (UTAUT) with the focus on three system characteristics; system flexibility, system enjoyment, and system interactivity. A total of 290 employees from the Jordanian Public Sector participated in the study. The findings revealed that system flexibility and system enjoyment have direct effects while system interactivity has an indirect effect on the employees' intention to use the web-based training system. In addition, system flexibility is proven to have the strongest relationship to users' intention to use the web-based training system.
\end{abstract}

Keywords: Technology acceptance, web-based training system, public sector, UTAUT.

\section{INTRODUCTION}

The web-based training system (WBTS) is among the Internet-based applications that enable the delivery of materials and information to employees anywhere and at anytime (Wang \& Jong, 2009; Chatzoglou, Sarigiannidis, 
Vraimaki \& Dianmantidis, 2009). This approach of training is also being accepted as an e-learning mode that provides many benefits to individuals and organizations with its capability to deliver all forms of contents such as video, audio, and animation. It enables employees to access training materials online through various mediums including computer and other mobile devices. In addition to its practicality, the implementation of web-based training is also considered very economical with its capacity to reduce training cost and time, while highly supporting the customers' activities during trainings (Hsia \& Tseng, 2008; Chatzoglou et al., 2009).

As Dadayan and Ferro (2005) and Venkatesh, Morris, Davis, and Davis (2003) reported that there is only a limited number of studies on the acceptance of information technology (IT) by the public sector employees, and studies on the acceptance of the web-based training system in the public sector environment is also not being extensively done (Walczak \& Scott, 2009; Chatzoglou et al., 2009). Most of the previous studies on the acceptance of similar systems were highly concentrated on educational environment rather than on public organizations (Chatzoglou et al., 2009; Dadayan \& Ferro, 2005). As internet technology has now become the base for training, the trend for organizations to rely on web-based training has increased especially when trainers and trainees are in long-distance areas. The implementation of the web-based training system should have been extensively explored and applied in organizations, either in the public or private sectors. Proper project-planning of an information system is very critical to the success of its implementation (Tan, 2011), as poor project-planning and implementation is always being reported as among the main reasons for information system failure (Ivonic, Mikinac, \& Perman, 2011).

Recent studies in relation to the acceptance of the ICT-based training systems have shown some issues in users' acceptance. Najafabadi, Hosseini and Mirdamadi (2009) identified human challenge as the most important barrier in implementing the ICT-based training system. In addition, organizational factor had also influenced the acceptance. The other important elements to have an efficient web-based training system are the instructional and technical requirements.

More studies should be conducted to explore in depth the issues and challenges that significantly drive the acceptance of the web-based training system. Factors such as flexibility, enjoyment, and interactivity of a system could also influence the acceptance of the system. To further understand and explore how Jordanian organizations can benefit from Internet technology and webbased applications, a study was carried out to investigate the acceptance of the 
web-based training system among the employees in Jordanian public sector organizations. The objective of this paper is therefore, to share the training needs and issues in the Jordanian public sectors, the theories of acceptance, the hypotheses formulation and the results of the study.

\section{LITERATURE REVIEW}

\section{ICT Training for Jordanian Public Employees}

A certified IT training known as International Computer Driving License (ICDL) has been implemented in Jordan since 2001. It is accepted as a standard for end user computer skills across the Kingdom. Most of the Jordanian ministries, including the Ministry of Education, Ministry of Health, Ministry of High Education, Ministry of Water and Irrigation, and Ministry of Information and Communication Technology (ICT) have adopted ICDL for their employees since 2003 (Advance Learning, 2008). As part of the ICDL incentives, employees have an opportunity to attend training without physically being in the training location. One of the possible approaches to complement a traditional training; as normally practised for ICDL training in Jordan, is allowing employees to take part in the training remotely. According to Hsia and Tseng (2008), the successful way to solve problems of attending traditional trainings is by applying a distance-training system, which is defined by Chatzoglou et al. (2009) as a computer-based distance-training that uses computer and network to convey the training materials and training resources to remote employees.

Several issues regarding the acceptance of a new system were debated in previous studies of the Information System. A study of Al-Rawashdeh (2011) on 100 public sector employees indicated high proportions of the employees who have PCs at home or at the workplace and have Internet access. About 92 per cent of them have regular computer access, 67 per cent have Internet access, and 81 per cent have e-mail accounts. The study brought up two issues regarding traditional training and computer-based training among the public employees in Jordan. The first issue was regarding the challenges faced by the public sector employees in Jordan in attending traditional training. About 82 per cent of them failed to attend the ICDL training classes due to the mismatch of their working time and the training time, as well as because of family commitment. In this respect, 74 per cent of the respondents indicated that the flexibility of the computer-based distance training system would help to overcome such problems. Furthermore, 55 per cent of them showed interest on multimedia materials over text books. The second issue was pertaining to the challenges encountered by employees in using the computer-based 
distance training system given by organizations for the ICDL training. Among the issues were (a) lack of support for computer maintenance, (b) employees had minimum confidence in using a new system, and (c) employees did not have very good computer skills. Other studies of e-training identified system functionality, human capabilities and finance resources as major influences on the acceptance of e-training in Jordanian organizations Harfoushi and Obiedat (2013). System functionality includes the flexibility aspects of the system's components such as the interactive materials, the response time, languages and the procedures given. The human capabilities highlight the needs of employees on e-learning activities, training and supporting materials.

In conclusion, these studies have recognized the existence of practical and human-based challenges in conducting traditional training as well as implementing the web-based distance-training system in the Jordan public sectors. It is worth noting that some of these challenges and issues could be related to the distance-training system characteristics such as system flexibility, system enjoyment and system interactivity, since employees' preferences are more on a flexible training mode with an interactive and friendly training system and materials.

\section{Acceptance of Information Systems}

Researchers had used different models and theories to explain the acceptance and adoption of IT, including the most frequent models of the Theory of Reasoned Action (TRA) (Ajzen \& Fishbein, 1980), the Innovation Diffusion Theory (IDT) (Rogers, 1983), the Theory of Planned Behaviour (TPB) (Ajzen, 1985), the Technology Acceptance Model (TAM) (Davis, 1989), and the Unified Theory of Acceptance and Use Technology (UTAUT) (Venkatesh, et al., 2003). Several studies have used UTAUT, a model that was introduced based on the combination of several other theories, in the e-learning context (Marchewka, Liu, \& Kostiwa 2007; Wong \& Jong, 2009). The theory portrays four determinants of an individual's intention to use technology, namely (a) performance expectancy, (b) effort expectancy, (c) social influence, and (d) facilitating conditions. Performance expectancy, like the usefulness of TAM, refers to the degree to which the technology used will enhance individuals' work performance. Effort expectancy, resembling to ease of the use of TAM mentions the degree of ease, which is associated with using a technology. Social influence, on the other hand, is about the opinions of other people who are important to an individual, whether to or not to use a technology. Finally, facilitating conditions is the degree of the existing technical infrastructure and organization's resources to support the use of technology (Wang \& Jong, 2009; \& Venkatesh et al., 2003). 
UTAUT explains 70 per cent of the technology acceptance behaviour intention whereas other models explain just over 40 per cent of acceptance (Venkatesh et al., 2003). This ability has made the model to be one of the most important IT acceptance theories among the models and theories of acceptance. Additionally, this model includes four moderators; age, gender, experience, and voluntariness of use that could explain the relationships between its constructs and behavioural intention to use information technology. These items moderate the relationship between performance expectancy and behavioral intention to use an information technology (Venkatesh et al., 2003); the relationship between effort expectancy and behavioural intention to use information technology (Venkatesh et al., 2003); the relationship between social influence and behavioural intention to use information technology; and finally, the relationship between facilitating conditions and the actual use of information technology (that is age and experience) (Marchewka et al., 2007; Venkatesh et al., 2003). Therefore, UTAUT is claimed as the most allencompassing IT adoption theory since it includes more factors affecting the intention of behaviour and satisfies the deficiencies of the other models and theories and combines them (Alzahrani \& Goodwin, 2012).

\section{FORMULATION OF HYPOTHESES}

A study of Al-Rawashed (2011) suggested that the acceptance of web-based training among the public sector employees could have been increased if employees had more flexibility, interactivity and enjoyment in using a training system. With the main purpose of the study being to assess the acceptance of a web-based training by the employees of public sector organizations, and UTAUT being successfully applied in the studies of IS acceptance, the study therefore decided to extend UTAUT with three factors that are related to the system characteristics: (a) system flexibility, (b) system enjoyment and (c) system interactivity (Hsia \& Tseng, 2008; Sahin \& Shelley, 2008; Abbad, Morris \& Nahlik, 2009; Sheng, Jue \& Weiwei, 2008; and Chatzoglou et al., 2009).

This study proposed seven hypotheses; four of them focused on the relationship between performance expectancy, effort expectancy, social influence, and facilitating condition on employees' intention to use WBTS (Venkatesh et al., 2003; Nanayakkara, 2005; Marchewka et al., 2007; Wang \& Jong, 2009). Three other hypotheses were regarding the influence of moderators; age, gender, and experience on the relationship between the other variables and the employees' intention. The hypotheses are as follows: 
H1. Performance expectancy will have a direct effect on the employees' intention to use the web-based training system.

H2. Effort expectancy will have a direct effect on the employees' intention to use the web- based training system.

H3. Social influence will have a direct effect on the employees' intention to use the web- based training system.

H4. Facilitating conditions will not have a significant effect on the employees' intention to use the web-based training system.

H5. The relationship between performance expectancy and behavioural intention will be moderated by age and gender.

H6. The relationship between effort expectancy and behavioural intention will be moderated by age, gender and experience.

H7. The influence of social influence on behavioural intention will be moderated by age, gender and experience.

Furthermore, this study also intended to test the relationship among system flexibility, system interactivity, system enjoyment and the employees' intention to use WBTS.

\section{System Flexibility}

The attraction of information and communications technology is its ability to enable flexible access to information and resources. Flexible access refers to access and use of information and resources at a time, place and pace that are suitable and convenient to individual learners rather than the teacher and/or the educational organization (Naidu, 2003). Many scholars introduced perceived flexibility as one of the critical factors to understand user's behavioural acceptance of the e-learning system (Hsia \& Tseng, 2008; Sahin \& Shelley, 2008; Nanayakkara, 2005). In the context of WBTS, flexibility could include flexibility of time, place and pace of using the system. Adapting this construct to examine the acceptance of the web-based training system by the public sector employees suggests that they will accept the web-based training system if they believe that they have access to and use of information and resources at a time, place and pace that are suitable and convenient of them. Therefore, the following hypothesis is proposed.

H8. System flexibility has a positive effect on employees' intention to use the web-based training system.

\section{System Interactivity}

The interactions between instructors and learners, learners themselves, and learners with the organization are the key elements of the learning 
process (Abbad, Morris, \& Nahlik, 2009). Adapting this construct (system interactivity) to the web-based training system suggests that the public sector employees think that using the web-based training system will enable them to interact between each other and among other members of the organization from any where at any time. Abbad et al. (2009) also suggested that system interactivity has an indirect impact on the user's intention to use the e-learning system through perceived usefulness and perceived ease of use. Additionally, Davis (1989) found that perceived usefulness and perceived ease of use fully mediates the effect of the system's characteristics on the user's intention to use e-mail technology. Consequently, because many scholars agree that perceived performance expectancy and perceived effort expectancy are similar to perceived usefulness and perceived ease of use (Venkatesh et al., 2003; Wang \& Jong, 2009; Marchewka et al., 2007), the following hypotheses are proposed.

H9. System interactivity has a positive impact on perceived performance expectancy.

H10. System interactivity has a positive impact on perceived effort expectancy.

\section{System Enjoyment}

Researchers found that activities using information technology should be enjoyable and accepted by the users (Sheng et al., 2008; Chatzoglou et al., 2009; Conci, Pianesi, \& Zancanaro, 2009; Chesney, 2006). Perceived enjoyment refers to the degree to which a user believes that using a system will be enjoyable, apart from the effect of such a system on his/her job performance (Conci et al., 2009). Adapting the system enjoyment factor to examine the acceptance of the web-based training system by public sector employees suggests that these employees will accept such a system if they believe that the process of using the system will be enjoyable. In the effect of perceived enjoyment, many studies indicated that perceived enjoyment has a direct effect on the user's intention to use the e-learning system and an indirect effect on behavioural intention through perceived ease of use and perceived usefulness (Sheng et al., 2008; Chatzoglou et al., 2009; Chesney, 2006). Thus, the following hypotheses are proposed.

H11. System enjoyment has a direct impact on perceived performance expectancy.

H12. System enjoyment has a direct impact on perceived effort expectancy.

H13. System enjoyment has a direct impact on employees' intention to use web-based training. 
In summary, this study has proposed thirteen hypotheses in an effort to determine the variables that influence the intention of public employees in using WBTS (Figure 1).

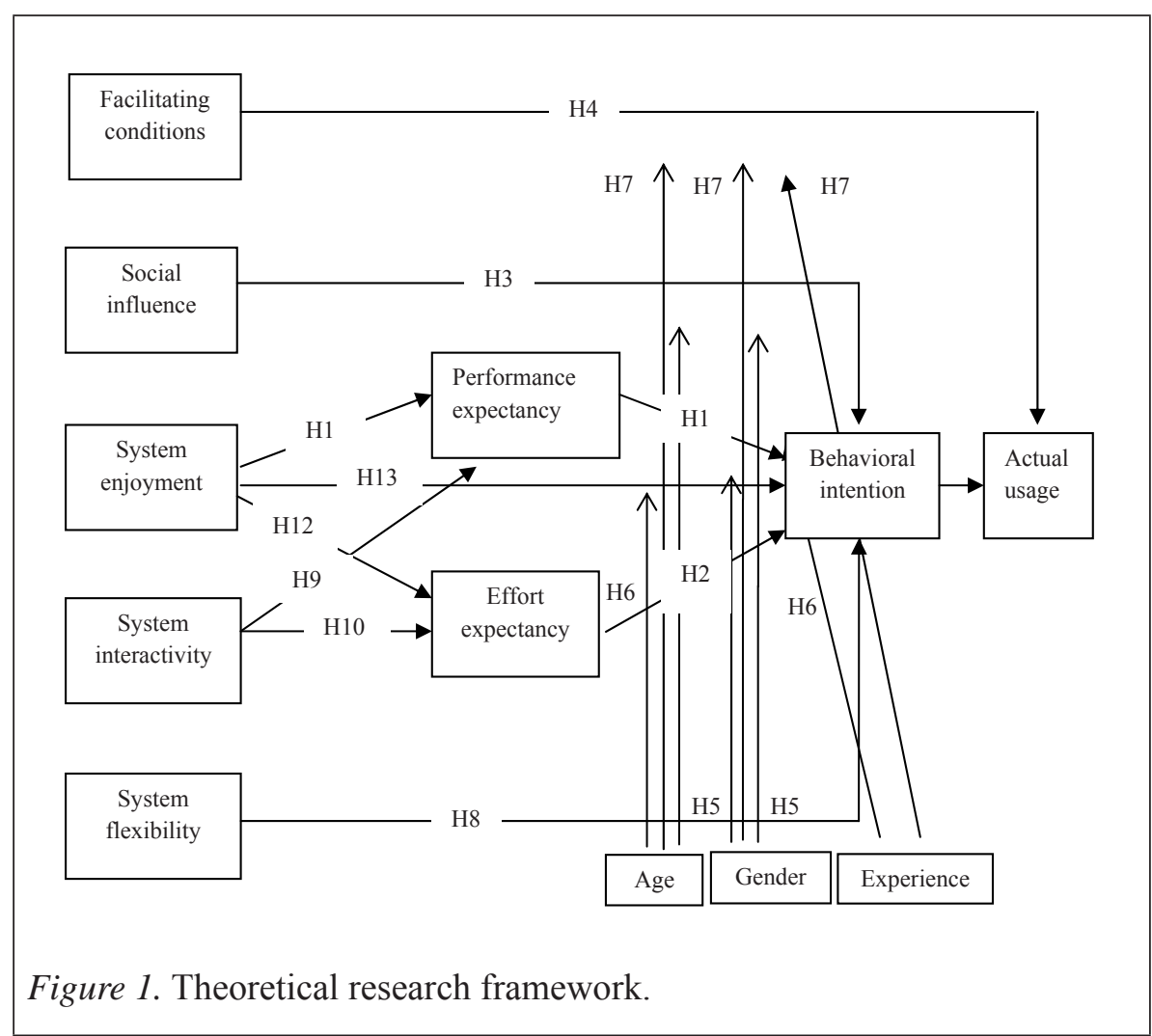

\section{METHODOLOGY}

\section{Research Approach and Sampling}

The study was a quantitative type as it was intended to investigate the relationship of several independent variables and the acceptance of the web-based training system by the employees of the public sector. The dependent variables of the study were behavioural intention and actual use (usage behaviour), while the independent variables were facilitating conditions, social influence, anxiety, self-efficacy, flexibility of distance learning, system enjoyment and system interactivity. The mediating variables were performance expectancy and effort expectancy and the moderating variables are gender, age, and experience. 
The study was conducted on the employees who worked for the Jordanian ministries, stayed in different places throughout Jordan and had attended ICDL's traditional training classes. A sample of such population was based on the Yamanes' (1967) equation which reveals that ${ }^{n}=\frac{N}{1+N(e)^{2}}$ where $n=$ sample of study, $\mathrm{N}=$ population of study, and e (precision) $=0.05$. The sample size of this research population, where $\mathrm{N}$ was 181,775 employees, was therefore determined to be 384. A questionnaire was designed and used to collect the data. A total of 400 questionnaires were distributed and the Structural Equation Model (SEM) was later used for the purpose of data analysis.

\section{Instruments Development and Validation}

The study employed questionnaires, which were modified based on previous literature. The questionnaires involved seven constructs, with each composed of several items. Eight sections were created, where the first section included information regarding the characteristics of the respondents such as age, gender, computer usage, internet access, experience of the distance-learning system. The rest of the other sections included questions that measured each of the model's constructs, namely performance expectancy, effort expectancy, social influence, facilitating conditions, system flexibility, system interactivity and system enjoyment. The last section included questions that measured employees' intention to use the web-based training system. The total number of items in the questionnaire was 50. Each item was measured using the 7-point Likert Scale (Appendix A). Appendix B shows the source of the items under each construct.

Validity and reliability are concerned with reducing the possibility of getting incorrect answers during the data-collection stage. In this study, content validity was carried out through the questionnaire pre-test process (Zikmund, 2003). The questionnaire was modified based on the comments which were received from ten public sector employees who responded to the questionnaire before it was distributed to the sample of the study. A pilot test was executed with the involvement of 50 public sector employees who were currently working with several government agencies in Jordan.

\section{DATA ANALYSIS AND FINDINGS}

\section{Profile of Respondents}

In total, only 350 public sector employees from 25 ministries received the questionnaire even though 400 questionnaires were earlier distributed. The balance was untraceable and due to some limitations, the study finally received 
only 290 (82 per cent) completed questionnaires. As shown in Table 1, the respondents consisted of 41 per cent males and 59 per cent females. Most of them were between 26 and 45 years old ( 68 per cent), while the others were under 25 years old ( 22 per cent) and over 45 years old ( 10 per cent). In terms of computer usage, all the respondents had computers for regular use. Additionally, they had good internet experience, since about 43 per cent of them used the Internet frequently and about 27 per cent spent many hours daily using the Internet.

In order to evaluate the construct validity and the reliability of the measurement items, the statistical software, AMOS 16.0, was used to carry out the Confirmatory Factor Analysis (CFA). Interestingly, the reliability of the instrument items had been tested using the composite reliabilities (CR), where the composite reliability $\mathrm{CR}=\left(\sum \text { standardized loading }\right)^{2} /\left(\sum\right.$ standardized loading $)^{2}+\sum \epsilon$, where $\epsilon$ is errors ) (Hair et al., 2010). The results, shown in Table 2, indicated that all the reliabilities based on the composite reliability test were greater than 0.9 , which is considered to be excellent.

Consequently, convergent validity discriminant validity tests were used to examine the validity of the research instrument (Hair et al., 2010). Convergent validity was carried out not only by Confirmatory Factor Analysis (CFA) and Composite Reliability, but also by Average Variance Extracted (AVE), where $\mathrm{AVE}=\sum\left(\mathrm{SMC}^{2}\right) /$ no. of items. According to Hair et al. (2010) the recommended value of AVE is above 0.5 (ideally $>0.7$ ). Table 3 shows that the instrument has high convergent validity.

Table 1

Respondents Profile

\begin{tabular}{|c|c|c|c|c|}
\hline & & Variable & $\begin{array}{c}\text { No. of } \\
\text { respondents }\end{array}$ & $\%$ \\
\hline \multirow[t]{2}{*}{ Gender } & Male & & 120 & $41 \%$ \\
\hline & & Female & 170 & $59 \%$ \\
\hline \multirow[t]{4}{*}{ Age } & $<25$ & & 66 & $22 \%$ \\
\hline & & $26-35$ & 118 & $41 \%$ \\
\hline & & $36-45$ & 78 & $27 \%$ \\
\hline & & $>46$ & 28 & $10 \%$ \\
\hline \multirow{3}{*}{$\begin{array}{l}\text { Have used a computer } \\
\text { Access of Internet network }\end{array}$} & & & 290 & $100 \%$ \\
\hline & & Can access & 218 & $75 \%$ \\
\hline & & Cannot access & 72 & $25 \%$ \\
\hline
\end{tabular}


Journal of ICT, 13, 2014, pp: 87-107

\begin{tabular}{llrr}
\hline & \multicolumn{1}{c}{ Variable } & $\begin{array}{c}\text { No. of } \\
\text { respondents }\end{array}$ & $\%$ \\
\hline Network type & Dialup & 24 & $8 \%$ \\
& High speed network & 192 & $67 \%$ \\
& No connection & 72 & $25 \%$ \\
Internet experience & & \\
& Spend many hours daily & 78 & $27 \%$ \\
& Frequently & 124 & $43 \%$ \\
& Never use & 88 & $30 \%$ \\
\hline
\end{tabular}

Table 2

Confirmatory Factor Analysis

\begin{tabular}{lccc}
\hline \multicolumn{1}{c}{ Constructs } & Items & Error & Loadings \\
\hline Performance Expectancy & PE 2 & 0.026 & .956 \\
& PE 3 & 0.026 & .965 \\
Effort Expectancy & PE 4 & 0.022 & .963 \\
System Interactivity & EE 5 & 0.025 & .972 \\
& EE 6 & 0.027 & .958 \\
System Enjoyable & SIN 1 & 0.033 & .921 \\
& SIN 2 & 0.032 & .928 \\
System Flexibility & SIN 3 & 0.037 & .951 \\
& SE 1 & 0.028 & .960 \\
Social Influence & SE 2 & 0.028 & .947 \\
& SF 1 & 0.039 & .974 \\
Facilitating Conditions & SF 2 & 0.041 & .964 \\
& SF 4 & 0.026 & .895 \\
& SI 1 & 0.041 & .897 \\
& SI 3 & 0.040 & .949 \\
& SI 4 & 0.043 & .890 \\
& FC 1 & 0.032 & .936 \\
Behavioural Intention & FC 2 & 0.032 & .958 \\
& FC 3 & 0.034 & .944 \\
& FC 5 & 0.030 & .927 \\
& BI 1 & 0.028 & .935 \\
& BI 2 & 0.029 & .961 \\
& BI 3 & 0.028 & .964 \\
& BI 4 & .90029 & \\
\hline
\end{tabular}


Table 3

Convergent Validity

\begin{tabular}{|c|c|c|c|}
\hline Observed variables & SMC & SMC2 & AVE \\
\hline PE2 & 0.91 & 0.83 & \\
\hline PE3 & 0.93 & 0.86 & \\
\hline PE4 & 0.93 & 0.86 & \\
\hline Performance Expectancy & & 2.55 & 0.85 \\
\hline EE5 & 0.92 & 0.85 & \\
\hline EE6 & 0.95 & 0.90 & \\
\hline Effort Expectancy & & 1.75 & 0.88 \\
\hline SIN1 & 0.85 & 0.72 & \\
\hline SIN2 & 0.86 & 0.74 & \\
\hline SIN3 & 0.90 & 0.83 & \\
\hline System Interactivity & & 2.29 & 0.76 \\
\hline $\mathrm{FC} 1$ & 0.88 & 0.77 & \\
\hline $\mathrm{FC} 2$ & 0.92 & 0.85 & \\
\hline $\mathrm{FC} 3$ & 0.89 & 0.79 & \\
\hline FC5 & 0.86 & 0.74 & \\
\hline Facilitating Conditions & & 3.15 & 0.79 \\
\hline SF1 & 0.95 & 0.90 & \\
\hline SF2 & 0.93 & 0.86 & \\
\hline SF4 & 0.82 & 0.67 & \\
\hline System Flexibility & & 2.43 & 0.81 \\
\hline SI1 & 0.82 & 0.67 & \\
\hline SI3 & 0.90 & 0.81 & \\
\hline SI4 & 0.81 & 0.66 & \\
\hline Social Influence & & & 0.71 \\
\hline SE1 & 0.92 & 0.85 & \\
\hline SE2 & 0.90 & 0.81 & \\
\hline System Enjoyment & & 1.66 & 0.83 \\
\hline BI1 & 0.87 & 0.76 & \\
\hline BI2 & 0.92 & 0.85 & \\
\hline $\mathrm{BI} 3$ & 0.93 & 0.86 & \\
\hline BI4 & 0.90 & 0.81 & \\
\hline Behavioural Intention & & 3.28 & 0.82 \\
\hline
\end{tabular}




\section{Validity of Research Model}

Additionally, in order to assess the overall metric model fit, five measures were applied, namely ratio chi-square to degrees of freedom $\left(\mathrm{X}^{2} /\right.$ d.f.), Root Mean Square of Error Approximation (RMSEA), Comparative Fit Index (CFI), Goodness of Fit Index (GFI), and Adjusted Goodness of Fit Index (AGFI). The final model of this study was obtained after deleting seventeen items (PE 1, PE 5, PE6, EE 1, EE 2, EE 3, EE4, SIN 4, SIN 5, SE 3, SE 4, SE 5, SF 3, SI 2, SI 5, BI 5 and FC 4). Consequently, it met all previous goodness of fit measures. Since $\left(X^{2} /\right.$ d.f. $)$ value was below the 3 threshold (Bollen, 1998), RMSEA's value was below the 0.08 threshold (Browne \& Cudeck, 1993), GFI value was above the 0.9 threshold (Bollen, 1998), AGFI value was above the 0.8 threshold (Bollen, 1998), while CFI value was above the 0.9 threshold (Smith \& McMillan, 2001). Table 4 presents the values of the previous model-fit measures.

Table 4

Values of Overall Model- Fit Measures

\begin{tabular}{lcc}
\hline \multicolumn{1}{c}{ Model-fit measures index } & $\begin{array}{c}\text { Recommended } \\
\text { values }\end{array}$ & Scores \\
\hline Chi-square to degrees of freedom (X $\mathrm{X}^{2}$ d.f.) & $\leq 3$ & 1.149 \\
Comparative Fit Index (CFI) & $\geq 0.90$ & .997 \\
Root Mean Square of Error Approximation (RMSEA) & $\leq 0.08$ & .023 \\
Adjusted Goodness of Fit Index (AGFI) & $\geq 0.80$ & .912 \\
Goodness of Fit Index (GFI) & $\geq 0.90$ & .933 \\
\hline
\end{tabular}

\section{Results and Hypotheses Discussion}

In the previous section, CFA was performed to assess the model's goodness of fit and loading of the research constructs with items which were used to measure them. In this section, a path analysis for structural model was conducted to examine the hypothesized relationships that help to predict employees' intention to use the web-based training system. Figure 2 explains the structural model with the assessed path coefficient and the adjusted coefficient of determination $\left(\mathrm{R}^{2}\right)$ scores, while Table 5 shows the overall results of hypotheses' examining. 


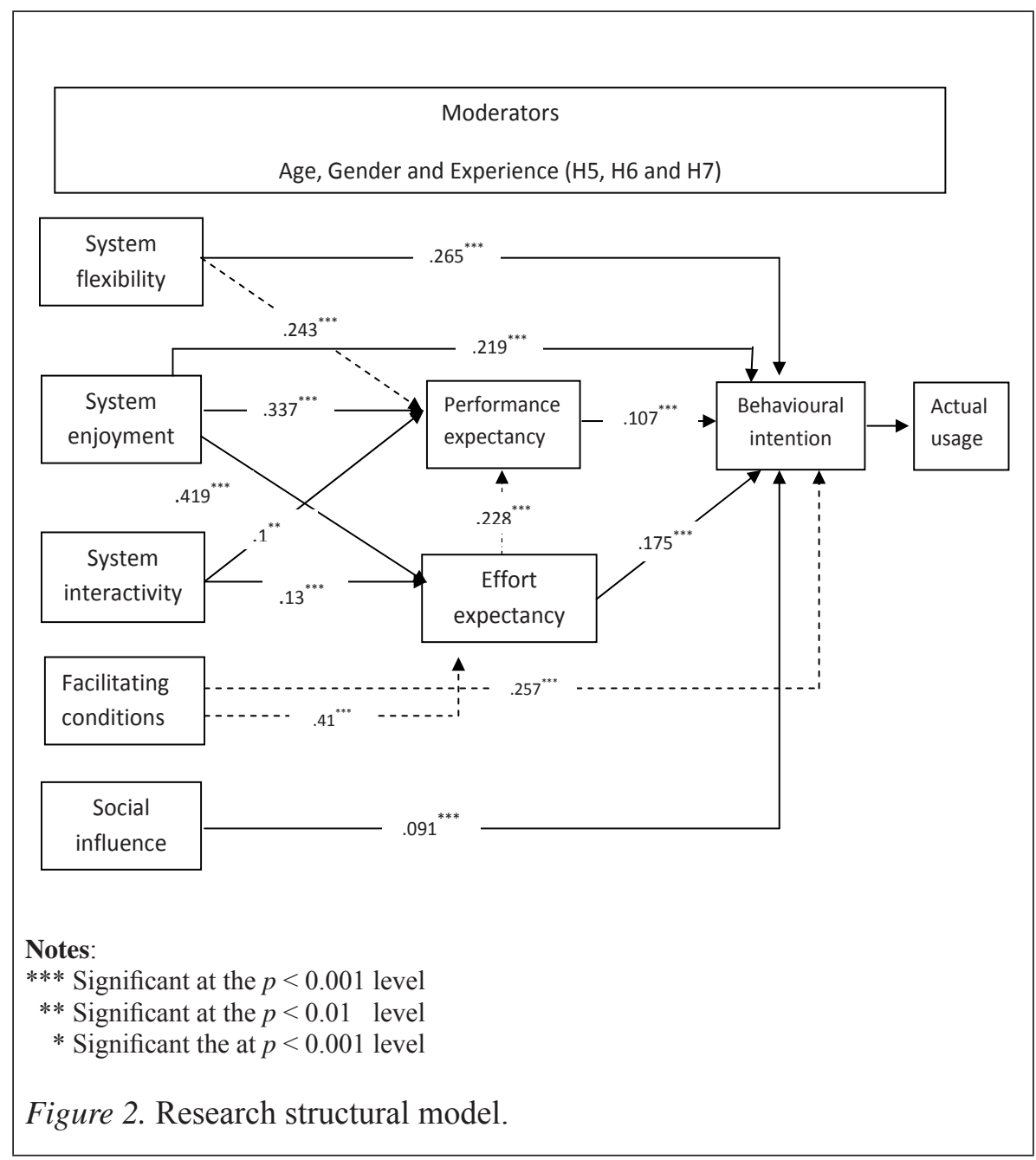

The first hypothesis (H1) stated that performance expectancy would have a direct effect on the employees' intention to use the web-based training system. This hypothesis was accepted since the result showed that there was a significant relationship between the performance expectancy and employees' intention to use the web-based training system $\left(0.107^{* * *}\right)$ (Table 5$)$, while the effect was moderated by age, gender and experience (H5) (the effect was important to younger male employees who had good Internet experience). The result was supported by prior studies (Venkatesh et al., 2003; Jong \& Wang, 2009; Marchewka et al., 2007), which found that performance expectancy affected the user's intention to use information technology. Further, Venkatesh et al. (2003) indicated that such relationship was moderated by age, gender, and experience. 
Table 5

\section{Hypotheses Testing Results}

\begin{tabular}{|c|c|c|c|}
\hline Hypotheses & Path & & Remarks \\
\hline H1 & Performance expectancy $\rightarrow$ intention & $0.107^{* * *}$ & accepted \\
\hline $\mathrm{H} 2$ & Effort expectancy $\rightarrow$ intention & $0.175^{* * *}$ & accepted \\
\hline $\mathrm{H} 3$ & Social influence $\rightarrow$ intention & $0.091^{* * *}$ & Accepted \\
\hline $\mathrm{H} 4$ & Facilitating condition $\rightarrow$ actual use & $\begin{array}{l}\text { No } \\
\text { relations }\end{array}$ & Excluded \\
\hline H5 & $\begin{array}{l}\text { Performance expectancy and intention relationship } \\
\text { is moderated by gender and age (for men) }\end{array}$ & yes & Accepted \\
\hline H6 & $\begin{array}{l}\text { Effort expectancy and intention relationship is } \\
\text { moderated by age, gender and experience. }\end{array}$ & yes & Accepted \\
\hline $\mathrm{H} 7$ & $\begin{array}{l}\text { Social influence and intention relationship is } \\
\text { moderated by age, gender and experience. }\end{array}$ & yes & Accepted \\
\hline H8 & System flexibility $\rightarrow$ intention & $0.265^{* * *}$ & Accepted \\
\hline H9 & $\begin{array}{l}\text { System interactivity } \rightarrow \text { performance } \\
\text { expectancy }\end{array}$ & $0.1^{* *}$ & Accepted \\
\hline H10 & System interactivity $\rightarrow$ effort expectancy & $0.132^{* * *}$ & Accepted \\
\hline H11 & $\begin{array}{l}\text { System enjoyment } \rightarrow \text { performance } \\
\text { expectancy }\end{array}$ & $0.337^{* * *}$ & Accepted \\
\hline H12 & System enjoyment $\quad \rightarrow \quad$ effort expectancy & $0.419^{* * *}$ & Accepted \\
\hline H13 & System enjoyment & $0.219^{* * *}$ & Accepted \\
\hline \multicolumn{4}{|c|}{ New detected relationships } \\
\hline \multicolumn{2}{|c|}{ Facilitating conditions $\rightarrow$ Intention } & $.257^{* * *}$ & Accepted \\
\hline \multicolumn{2}{|c|}{ Effort expectancy $\rightarrow$ Performance expectancy } & $.228^{* * *}$ & Accepted \\
\hline \multicolumn{2}{|c|}{ Facilitating conditions $\rightarrow$ Effort expectancy } & $.410^{* * *}$ & Accepted \\
\hline \multicolumn{2}{|c|}{ System flexibility $\rightarrow$ Performance expectancy } & $.243^{* * *}$ & Accepted \\
\hline
\end{tabular}

The second relationship (H2) indicated that effort expectancy had a direct effect on the employees' intention to use the web-based training system. This hypothesis was also accepted, since the statistical result indicated that there was significant relationship between effort expectancy and employees' intention to use the web-based training system $\left(0.175^{* * *}\right)$ (Table 5). However, this relationship was not moderated by gender, age, and experience (H6). This result is consistent with that of Taylor and Todd (1995) and Davis (1989), which confirmed that effort expectancy (ease of use) affected performance expectancy (usefulness) and user attitude. 
The third hypothesis (H3) showed a significant relationship between social influence and employees' intention to use the web-based training system. Consequently, the statistical results indicated that there was a relationship $\left(0.091^{* * *}\right)$ (Table 5) between social influence and the user's intention to use the web-training system, while the latter's effect was moderated by age, gender and experience (H7). This finding is in line with those of Venkatesh et al. (2003) and Venkatesh and Morris (2000), who argued that the effect of social influence on an individual's intention to use information technology was more salient to older women and decreased with experience. Focusing in this relationship, it can be assumed that, employees paid much attention to the opinions of other people, who were important to them, when they intended to use the web-based training system.

The fourth hypothesis (H4) indicated that facilitating conditions do not have an effect on the employees' intention to use the web-based training system. This hypothesis was rejected, since the statistical result revealed that there was a significant relationship between facilitating conditions and employees' intention $\left(0.257^{* * *}\right)$ (Table 5). This result has also been confirmed by Thompson, Higgins and Howell (1991) and Ajzen (1991). However, it contrasts with Venkatesh et al. (2003) who argued that the facilitating conditions did not have an effect on an individual's intention to use an information system, but it had a direct effect on the actual use beyond that explained by behavioural intention.

Similar to other studies (Hsia \& Tseng, 2008; Nanayakkara, 2005; Lim, Kia, \& Kok, 2008), the relationship between flexibility of the web-based training and the employees' intention to use web training (H8) in this study was confirmed $\left(0.265^{* * *}\right)$ (Table 5). This relationship possibly indicates that a trainer intends to use a web-training system if he/she believes that he/she can access the system from anywhere at any time. In other words, trainees would participate in the e-training process if they believed that they could choose their training equipment and time themselves. Furthermore, similar to Hsia and Tseng (2008), there was also a relationship between system flexibility and performance expectancy $\left(0.243^{* * *}\right)$ (Table 5).

As for System interactivity, this study provides evidence that it has a positive effect on performance expectancy $\left(0.1^{* *}\right)$ (Table 5) (H9) and effort expectancy $\left(0.132^{* * *}\right)$ (Table 5) (H10). It can be assumed that when employees intend to use web-based training to interact with members of an organization, they also believe that web-based training will enhance their training performance and make the training much easier. This result however contrasted with Abbad et al. (2009). 
Hypothesis 11, 12, and 13 highlighted that system enjoyment had a direct impact on perceived performance expectancy, perceived effort expectancy, and the employees' intention. These hypotheses were accepted, with results on performance expectancy $\left(0.337^{* * *}\right)$, effort expectancy $\left(0.419^{* * *}\right)$, and employees intention $\left(0.219^{* * *}\right)$ (Table 5). These results supported the studies of Chatzoglou et al. (2009) and Abbad et al. (2009), which indicated that there are significant relationships between system enjoyment usefulness (performance expectancy), ease of use (effort expectancy) and behavioural intention. In summary, the study concluded that six direct relationships were statistically significant to the employee's intention (Table 5): relationships between (a) performance expectancy, (b) effort expectancy, (c) system enjoyment, (d) facilitating conditions, (e) system flexibility and (f) social influence with the employees' intention to use the web-based training system. The most significant relationship was determined to be between system flexibility and user's intention (0.265), which suggested that WBTS (information and related resources) should be flexible and available to be accessed at any time and place.

The second important relationship was between facilitating conditions and employee's intention (0.257) (Table 5). The result implies that an organizations' effort to improvise the supports (knowledge and facilities) should alleviate and the increase employees' intention and interests in using WBTS. The third important relationship was between system enjoyment and employees' intention (0.219) (Table 5). In this respect, user interface and training-materials format should be pleasant and easy to use. Furthermore, the process of using the system should be made friendlier and supportive. The fourth important direct relationship was between effort expectancy and employees' intention (0.175) (Table 5). The relationship of the employees' intention with performance expectancy $(0.107)$ (Table 5) and social influence $\left(0.091^{* * *}\right)$ (Table 4) were the last two important relationships.

Therefore, this study found that there are four factors which have direct impact on performance expectancy and effort expectancy. These factors are system flexibility, system interactivity, system enjoyment and facilitating conditions. The existence of these factors will make the system much more meaningful, useful and easier to use. These results are consistent with that of Davis (1989) who indicated that system characteristics have impact on usefulness and ease of use. 


\section{CONCLUSION}

The web-based training system is an alternative training to public sector employees especially when they have limitations in attending traditional or face-to-face training due to distance, time, and family constraints. A preliminary study on the Jordanian public sector employees has highlighted the occurrence of a few challenges in the web-based training system implementation, which could be related to the system's characteristics such as system flexibility, system enjoyment and system interactivity. For further information on the acceptance of WTBS among the public sectors in relation to the three system characteristics, a survey was conducted that involved the participation of the Jordanian public sector employees. The Unified Theory of Acceptance and Use Technology (UTAUT) was used with the focus on the three system characteristics; system flexibility, system enjoyment, and system interactivity, besides other factors; facilitating condition, social influence, effort expectancy, and performance expectancy.

Two system characteristics system flexibility and system enjoyment with four other factors including facilitating conditions, performance expectancy, effort expectancy, and social influence have proven to have direct effects on the employee's intention to use WBTS. These findings are very vital to support the government's initiative to further enhance the flexibility and features of any web-based training system towards facilitating employees' knowledge and skills development. On the other hand, system interactivity has also been proven to have a positive impact on perceived performance expectancy and effort expectancy, which eventually influences the intention of an employee to use WBTS. These findings suggest that more interactive features should be integrated into a system to facilitate users to use a system remotely. More interactive elements including chat, forum, interactive QA session, and online assessment should be highly prioritized in designing a web-based training system.

The result disclosed that social influence does have an impact on the employees' intention to use WBTS. Employees give attention and take action on the opinions given by people who are important to them (e.g. their supervisors or their peers), on the subject of WBTS. This has affected their decision. Facilitating conditions also have a strong effect on the employees' intention to use the web-based training system. Knowledge and resources provided by employers or government agencies to facilitate the use of WBTS are necessary in the training process. The finding proved that the availability of those facilities is a concern in encouraging employees to use WBTS. 
Therefore, managers should take into account employees' knowledge and resources, which are needed in the training process, in order to motivate and increase employees' interest to use the web-based training system.

\section{REFERENCES}

Abbad, M. M., Morris, D., \& Nahlik, C. (2009). Looking under the Bonnet: Factors affecting student adoption of e-Learning Systems in Jordan. International Review of Research in Open and Distance Learning, 10(2).

Advance Learning (2008). ICDL in the Middle East. Retrieved from http:// www.eu.advancelearning.com

Ajzen, I. (1985). From intentions to actions: A theory of planned behavior. In J. Kuhl, \& J. Beckman (Eds.), Action-control: From cognition to behaviour (pp. 11-39). Heidelberg: Springer.

Ajzen, I. (1991). The theory of planned behavior. Organizational Behavior and Human Decision Processes, 50(2), 179-211.

Ajzen, I., \& Fishbein, M. (1980). Understanding attitudes and predicting social behaviour. New Jersey: Prentice-Hall.

Al-zahrani, M. E., \& Goodwin, R. D. (2012). Towards a UTAUT-based model for the study of e government citizen acceptance in Saudi Arabia. World Academy of Science, Engineering and Technology, 64, 8-14.

Al-Rawashdeh, T. A. M. (2011). The extended UTAUT acceptance model of computer-based distance training system among public sector's employees in Jordan (Unpublished doctoral dissertation). Universiti Utara Malaysia.

Bollen, K. A., \& Laing, J. (1988). Some properties of Hoelter's CN. Sociological Methods and Research, 16, 492-503.

Bollen, P. M. (1998). Structural equations with latent variables. New York: John Wiley \& Sons.

Brown, K. G. (2001). Using computers to deliver training: Which employees learn and why? Personnel Psychology, 54(1), 271-296.

Browne, M. W., \& Cudeck, R. (1993). Alternative ways of assessing model fit. In K. A. Bollen, Long testing structural equation models (pp. 136-162). Newbury Park, CA: Sage Publication.

Chatzoglou, P. D., Sarigiannidis, L., Vraimaki, E., \& Diamantidis, E. (2009). Investigating Greek employees' intention to use web-based training. Computers \& Education, 53, 877-889. 
Chesney, T. (2006). An acceptance model for useful and fun information system. Interdisciplinary Journal of Humans in ICT Environment, 2(2), 225-235.

Conci, M., Pianesi, F., \& Zancanaro, M. (2009). Useful, social and enjoyable: Mobile phone adoption by older people. Human-Computer Interaction - INTERACT 2009, Springer, 5726, 63-76.

Dadayan, L., \& Ferro, E. (2005). When technology meets the mind: A comparative study of the Technology Acceptance Model. International Conference on Electronic Government, 3591,137-144.

Davis, F. (1989). Perceived usefulness, perceived ease of use, and user acceptance. MIS Quarterly, Sep, 13(3), 318-323.

Hair, J. F., Black, W. C., Babin, B. J., \& Anderson, R. E. (2010). Multivariate data analysis (7th ed.). New Jersey: Pearson Education.

Hsia, J. W., \& Tseng, A. H. (2008). An enhanced Technology Acceptance Model for e-learning systems in high-tech companies in Taiwan: Analyzed by structural equation modeling (pp. 39-44). International Conference on Cyberworlds.

Harfoushi, O., \& Obiedat, R. (2013). E-training acceptance factors in business organizations. International Journal of Emerging Technologies in Learning, 6(2), 15-18.

ICDL US (2009). ICDL foundation. Retrieved from http://www.icdlus.com

Ivanovic, S., Mikinac, K., \& Perman, L. (2011). CRM development in hospitality companies for the purpose of increasing the competitiveness in the tourist market. Journal of Economics, 2(1), 59-68.

Lim, B. C., Kian, H. S., \& Kock, T. W. (2008). Acceptance of e-learning among distance learners: A Malaysian perspective. Proceedings of Ascilite Melbourne 2008, 541-551.

Marchewka, J., Liu, C., \& Kostiwa, K. (2007). An application of the UTAUT model for understanding student perceptions using course management software. Communications of the IIMA, 7(2).

Najafabadi, M. O, Hosseini, S. J. F., \& Mirdamadi, S. M. (2009). An ordinal factor analysis of requirements and challenges of information and communication technology system to train private agricultural insurance brokers in Iran. Journal of Information and Communication Technology, 8, 103-114.

Naidu, S. (2003). E-learning: A guidebook of principles, procedures and practices. Commonwealth of Learning. Commonwealth Educational Media Centre for Asia. 
Nanayakkara, C. (2005). A model of user acceptance of learning management systems: A study within tertiary institutions in New Zealand. International Journal of Learning, 13(12), 223-232.

Rogers, E. M. (1983). Diffusion of innovations (3rd ed.). New York: Free Press.

Sahin, I., \& Shelley, M. (2008). Considering students' perceptions: The distance education student satisfaction model. Educational Technology \& Society, 11(3), 216-223.

Sheng, Z., Jue, Z., \& Weiwei, T. (2008). Extending TAM for online learning systems: An intrinsic motivation perspective. Tsinghua Science and Technology, 13(3), 312-317.

Smith, T. D., \& McMillan, B. F. (2001). A primer of model fit indices in structural equation model. Paper presented at the annual meeting of the southwest educational research association, February 1-3, New Orleans, LA.

Tan, S. (2011). How to increase your IT project success rate. Gartner Research: ID Number G00209668.

Taylor, S., \& Todd, P. (1995). Understanding information technology usage: A test of competing models. Information Systems Research, 6(2), 144-176.

Thompson, R. L., Higgins, C. A., \& Howell, J. M. (1991). Personal computing: Toward a conceptual model of utilization. MIS Quarterly, 124-143.

Venkatesh, V., \& Morris, M.G. (2000). Why don't men ever stop to ask for direction? Gender, social influence, and their role in technology acceptance and usage behavior. MIS Quarterly, 24(1), 115-139.

Venkatesh, V., Morris, M. G., Davis, G. B., K., \& Davis, F., D. (2003). User acceptance of information technology: Toward a unified view. MIS Quarterly, 27(3), 425-478.

Walczak, S., \& Scott, J. E. (2009). Cognitive engagement with a multimedia ERP training tool: Assessing computer self-efficacy and technology acceptance. Information and Management, 46, 221-232.

Wang, T. S., \& Jong, D. (2009). Students acceptance of web-based learning system. 2009 International Symposium on Web Information System and Application, 533-536.

Zikmund, W., G. (2003). Business research methods (7th ed.). Mason: Thomson/South-Western. 